\title{
Raising standards in relation to Section 136 of the Mental Health Act 1983
}

\author{
Michele Hampson
}

\begin{abstract}
SUMMARY
Despite the guidance published in revised Codes of Practice and by the Royal College of Psychiatrists, implementation of Section 136 of the Mental Health Act 1983 is still variable. Government funding in England to establish places of safety in psychiatric facilities has been effective but custody suites are still used excessively, especially for those who are brought in intoxicated. Patients feel criminalised by this use of custody suites and by the use of police vehicles rather than ambulance transport for conveyance to the place of safety. There is often a delay in commencing the assessment and the first doctor does not always have Section 12 approval as recommended in the Codes of Practice. The importance of the local Section 136 group tasked with developing and overseeing the implementation of local policy and monitoring is highlighted. There is a need for monitoring locally, but ideally in a form that can be used nationally for benchmarking and research.
\end{abstract}

\section{DECLARATION OF INTEREST}

None.

Section 136 of the Mental Health Act 1983 applies in England and Wales only. It is estimated that it was used more than 16000 times during 2005-2006, yet it has received comparatively little attention.

\section{What is Section 136?}

Section 136 (Box 1) is the power that allows a police officer to detain someone whom they believe to be mentally disordered and in need of urgent care and control. The individual must be in a public place, defined as a place to which the public have access, and can be taken to a place of safety to enable a mental health assessment to take place.

In 2007, Section 136 was amended to permit patients to be moved from one place of safety to another. This was welcomed as it allows patients to be assessed and treated in the most appropriate environment. For example, they can be transferred from the custody suite to a hospital place of safety if their behaviour settles, or to the hospital to

receive emergency medical treatment if required. The Royal College of Psychiatrists also suggested reducing the maximum duration of detention from 72 hours to 24 hours and the introduction of a statutory form. Neither of these recommendations was accepted.

\section{Setting standards of care for Section 136}

Good practice guidance is available in the two Mental Health Act Codes of Practice, one for England, the other for Wales (Department of Health 2008; Welsh Assembly Government 2008). For England, the College published much more detailed standards that were produced and agreed by all involved agencies, including monitoring organisations (Royal College of Psychiatrists 2008). That report (CR149) also offers practical guidance on the physical environment of the Section 136 suite, the role of staff and guidance on the monitoring process. A further College report (CR159), detailing differences between the two Codes and agreeing standards across both countries, is now available (Royal College of Psychiatrists 2011). Local policies and procedures should mirror these national standards, although they may require modification to reflect local circumstances. Both the Codes and the College recommend the establishment of a local Section 136 group to advise on and monitor standards.

B0X 1 Section 136 of the Mental Health Act 1983

1 If a constable finds in a place to which the public have access a person who appears to him to be suffering from mental disorder and to be in immediate need of care or control, the constable may, if he thinks it necessary to do so in the interests of that person or for the protection of other persons, remove that person to a place of safety within the meaning of section 135 above.
ARTICLE
Michele Hampson is a consultant psychiatrist working on an assessment ward in Nottingham, UK. She is author of the Royal College of Psychiatrists' report on standards in relation to Section 136 and chairs a multi-agency group to support its implementation. She also chairs the General and Community Psychiatry Faculty of the College. Correspondence Dr Michele Hampson, A46 South Block, Queens Medical Centre, Derby Road, Nottingham NG7 2UH, UK. Email: michele.hampson@nottshc.nhs.uk 


\section{The Section 136 care pathway}

\section{Initial detention and transfer}

The patient (the term used in the Act and the Codes of Practice) should be in a 'public place'. This can include a cinema or a pub but not a private garden or hospital ward. If the person is committing a breach of the peace in a private place, they may be removed and can then be legitimately detained under Section 136. (The Mental Capacity Act 2005 does apply in private places and it may be applicable for police use. The patient should then be assessed in a hospital emergency department.) If a significant offence has been committed, the person should first be charged. This procedure is supported by user organisations. Where appropriate, a Mental Health Act assessment can then take place in the custody suite at the police station.

The police should inform the individual that they have not been charged with a criminal offence but are being detained under the Mental Health Act. An ambulance should be used wherever possible for conveyance. The ambulance provider should respond within 30 minutes, unless there is local agreement to upgrade to more urgent response time if there is no privacy in the public place to protect the person's dignity. The ambulance clinician will give any immediate medical attention required and assist the police in determining the most appropriate place of safety. The police should escort the patient, because it is not clear in the Act that this duty can be delegated.

There should be an assumption that the patient will be searched under the Police and Criminal Evidence Act 1984 (PACE), unless there are clear grounds for not doing so.

\section{Choice of place of safety}

All guidance states that the custody suite should only be used as the place of safety in exceptional circumstances. This arises when the patient is too disturbed to be managed safely elsewhere. If they require urgent medical attention, they should be taken to an emergency department. In all other cases, they should be taken to a Section 136 suite in a psychiatric facility, here referred to as the Section 136 suite.

The Section 136 suite should accept those who are intoxicated with alcohol or drugs, unless they require urgent medical attention or their behaviour is too disturbed. All facilities should be capable of managing moderately disturbed behaviour. The place of safety should agree to accept the patient before the police start the journey, unless it is a medical emergency.
Other units can be used as places of safety, such as a psychiatric intensive care facility, a child and adolescent unit or residential facility for the elderly. It is recommended that these options be discussed with mental health professionals first. The person in charge of the proposed place of safety must agree that they can safely manage the patient before the patient commences their journey.

A patient may be transferred between places of safety if the benefits of using a more appropriate environment and staff familiar with the patient outweigh the risk of delay in completing the assessment. The guiding principles of the Codes of Practice should be used to reach the decision. Thus, patients whose behaviour settles or who have received the appropriate medical intervention may be transferred to a Section 136 suite or be moved to the Section 136 suite of the hospital normally responsible for their care.

\section{Care in the Section 136 suite}

Healthcare professionals should be present to greet the patient on arrival at the Section 136 suite. They should conduct an immediate risk assessment and receive a verbal handover from the police. Staff should usually be able to take over responsibility for the patient within 20 minutes, during which time the police should complete any written documentation. The staff must be able to summon extra help at short notice and the environment must be suitable to manage moderately disturbed behaviour without police support.

The competencies required of Section 136 suite staff include physical intervention - the correct term for restraint according to the National Institute for Health and Clinical Excellence (NICE; 2005) - and the administration of medication. Medication can be given to a consenting capacitous patient or, subject to the conditions of the Mental Capacity Act 2005, if the patient lacks capacity. Where community teams staff the Section 136 suite, the local monitoring group must be satisfied that they can always attend the suite at short notice and that staff have the required competencies. Consideration should be given to having dedicated Section 136 nurses who can be assigned to other wards or facilities if not required on the suite.

The prime duty of the Section 136 suite staff is to ensure the safety of the patient and carers. Additional considerations are comfort, prompt assessment and, if appropriate, the initiation of treatment. They often will contact the approved mental health practitioner (AMHP) for the police and support the assessment process by helping to arrange the attendance of doctors and gathering background information. They should have 
access to medical staff to provide urgent medical assessment and treatment and assistance with risk management.

If an alternative place of safety is used, the Section 136 staff may attend to offer support to the patient and advice to those responsible for the patient's care. They may then assist with the transfer of the patient.

\section{The Mental Health Act assessment}

Ideally, there should be a joint assessment by an approved mental health practitioner and Section 12 approved doctor. A joint assessment by two doctors is preferable if it is clear that the patient is likely to require detention. The patient must be discharged immediately from Section 136 if they are not found to require ongoing detention. A custody sergeant has similar powers to discharge a patient under the Police and Criminal Evidence Act 1984. However, they are advised to discuss the matter first with an approved mental health practitioner. The Codes of Practice recommend that the medical opinion is provided by a Section 12 approved doctor. Many forensic physicians (the new title for forensic medical examiners or police surgeons) and junior psychiatric trainees do not have Section 12 approval. It is therefore recommended that their role is to address fitness to be detained in custody suites, safety and physical health issues, and not to conduct the formal mental health assessment.

Where a patient is seen first by a Section 12 approved doctor and is discharged, the patient should still be advised to wait to see the approved mental health practitioner, who may be able to offer advice and support. The patient is not obliged to do so, therefore it is preferable that the approved mental health practitioner and doctor conduct a joint assessment.

The Code of Practice for Wales recommends that a patient under 18 years old or recently referred to adult services should be assessed by an approved mental health practitioner and a psychiatrist with specialist expertise in working with children. Similarly, patients with intellectual disabilities should be assessed by specialists. The English Code of Practice recommends that specialists should be used where it would not cause undue delay.

The approved mental health practitioner should collect background information or delegate this to the Section 136 suite staff. The interview should commence within 3 hours unless there are legitimate reasons for a delay, such as the need to gain more information or waiting for the patient to be fit for interview. Complex assessments may be aided by professionals who have knowledge of the patient.
The assessment process does not differ from other Mental Health Act assessments. The guiding principles for England or for Wales should be applied.

On completion of the assessment the patient should be transferred or discharged promptly. This implies the availability of a suitable psychiatric bed locally and a fund to pay for transport home where necessary. Staff should complete their paperwork and ensure that this includes the data required for monitoring purposes (see below).

\section{Common problems with Section 136 care}

\section{Professional perspectives}

The roles and concerns of each professional group are listed in Table 1.

\section{User and carer views}

The key concern of users and carers that have emerged from focus groups is the apparent criminalisation of the patient with mental illness. The arrest (as it is called under Police and Criminal Evidence Act 1984) may be public and therefore potentially embarrassing and stigmatising for the patient and carers. For members of the Black community, it is reminiscent of the 'Sus' law (the police stop and search power on the basis of suspicion, abolished in 1981). This is then compounded by the common use of police vehicles to transfer the patient to the place of safety. Many are still taken to custody suites for the assessment, especially if under the influence of alcohol or drugs. The custody suite environment may be frightening and inhospitable (Box 2). Patients report receiving little information verbally or in writing about the Section 136 process and are not kept informed of how long they are likely to have to wait for the assessment. The wait can be long and, with little distraction, can feel even longer. There is a concern that Section 136 assessments may routinely be disclosed as part of criminal record checks, whereas the need to do so should depend on individual circumstances.

\section{Common misconceptions in relation to Section 136}

There are a number of common misconceptions relating to care under Section 136, as summarised in Box 3 and explained below.

‘Regular use of the custody suite as a place of safety is acceptable'

Research found that in 2005-2006 more than two-thirds of Section 136 assessments took place in custody suites in England (Docking 2007). The 
TABLE 1 Professional roles and concerns and the Section 136 care pathway

\begin{tabular}{|c|c|c|}
\hline Professional group & Roles & Concerns \\
\hline Police officer & $\begin{array}{l}\text { Transfer patient promptly from public place to place of } \\
\text { safety and hand them over to care of healthcare staff, unless } \\
\text { taken to custody suite owing to disturbed behaviour. }\end{array}$ & $\begin{array}{l}\text { Delay in getting ambulance transport. } \\
\text { Expectation that they will have to remain at place of safety until } \\
\text { assessment complete. }\end{array}$ \\
\hline Custody sergeant & $\begin{array}{l}\text { The safety and well-being of patient under their care. } \\
\text { To ensure assessment is done as quickly as possible. }\end{array}$ & $\begin{array}{l}\text { Overuse of custody suites due to lack of suitable Section } 136 \\
\text { suites or such suites refusing to take those under influence of } \\
\text { drugs or alcohol. } \\
\text { Custody suite not designed for the care of the mentally ill. } \\
\text { Lack of access to support and advice regarding care of patient } \\
\text { from mental health professionals. } \\
\text { Delay in completion of assessments and transfer. }\end{array}$ \\
\hline Ambulance service & $\begin{array}{l}\text { Assist in safe and timely transfer to place of safety and } \\
\text { where necessary between places of safety and to hospital. } \\
\text { Provision of emergency medical assessment and treatment. } \\
\text { Support police in determining most appropriate place of } \\
\text { safety. }\end{array}$ & $\begin{array}{l}\text { Difficulty in meeting the recommended response time of } \\
30 \text { minutes. }\end{array}$ \\
\hline $\begin{array}{l}\text { Hospital place of safety staff } \\
\text { Mental health staff }\end{array}$ & $\begin{array}{l}\text { To facilitate a timely assessment and prompt discharge of } \\
\text { the patient. } \\
\text { To offer care and support to both patient and carers and } \\
\text { safety of all involved in process. }\end{array}$ & $\begin{array}{l}\text { Lack of suitable facility and staffing levels for managing } \\
\text { moderately disturbed behaviour. } \\
\text { If no dedicated Section } 136 \text { staff, their deployment in the suite } \\
\text { may leave another area under-resourced. } \\
\text { Access to medical support to review safety issues and physical } \\
\text { health while waiting for formal assessment. }\end{array}$ \\
\hline Emergency department staff & $\begin{array}{l}\text { To provide emergency medical attention (police generally } \\
\text { expected to remain to ensure safety of patient). } \\
\text { Prompt transfer when safe to do so. }\end{array}$ & $\begin{array}{l}\text { Lack of support from mental health professionals and delays in } \\
\text { transfer or in completing assessment. } \\
\text { Problems ensuring safety of patient without police support. }\end{array}$ \\
\hline $\begin{array}{l}\text { Approved mental health } \\
\text { practitioner }\end{array}$ & $\begin{array}{l}\text { To carry out assessment with Section } 12 \text { approved doctor } \\
\text { in suitable environment and manner, having obtained } \\
\text { background information to assist assessment. } \\
\text { Access to interpreters if required. }\end{array}$ & $\begin{array}{l}\text { Lack of suitable environment for assessment. } \\
\text { Lack of availability of approved mental health practitioners and } \\
\text { Section } 12 \text { approved doctors to commence assessment promptly } \\
\text { Delays in accessing bed for admission or funding for transport if } \\
\text { discharged. }\end{array}$ \\
\hline Section 12 approved clinicians & $\begin{array}{l}\text { To respond promptly and to conduct Mental Health Act } \\
\text { assessment. }\end{array}$ & $\begin{array}{l}\text { Disruption to planned activities. } \\
\text { Lack of staff, especially where child or intellectual (learning) } \\
\text { disability expertise required. }\end{array}$ \\
\hline $\begin{array}{l}\text { Psychiatric trainees and } \\
\text { forensic physicians (police } \\
\text { surgeons) }\end{array}$ & $\begin{array}{l}\text { Provide immediate assessment and management where } \\
\text { needed, including physical health issues; in custody suite, } \\
\text { includes assessment of fitness to be detained in custody. } \\
\text { Complete Mental Health Act assessment if have Section } 12 \\
\text { approval. }\end{array}$ & \\
\hline
\end{tabular}

government for England provided $£ 130$ million for the development of Section 136 suites which, despite the absence of funding for staff, appears

BOX 2 The custody suite as a place of safety: extracts from a patient's account

'A police station cell, by its very nature has to be a bare, controlled environment, for obvious reasons. As a place of safety for a vulnerable person it offers no comfort, poor communication, little interaction and a sense of extreme solitude.'

'Although the physical environment was harsh a little discomfort never harmed anyone. The lack of suitably qualified supervising staff was, in my opinion, a very major short coming. The sense of extreme solitude would have been lessened if what conversations there were had not taken place through a locked door.'

(Mental Health Act Commission 2009: p. 132) to have been effective. A survey of police forces in June 2009 found that in England all but three forces had access to hospital places of safety (A. Hunt, personal communication 2010). However, the picture is of ongoing regular use of the custody suite in many areas (of 15 forces able to provide data, only 3 estimated use to be less than $15 \%$ and 9 estimated it to be more than 50\%). In particular, police forces report that some Section 136 suites will not take anyone who has consumed alcohol or drugs, regardless of their behaviour or degree of intoxication.

'Police should routinely transport patients to the place of safety'

This may be pragmatic, as the patient is quickly and safely removed and it enables the police to get back to their regular duties. However, use of police vehicles gives the impression to the patient and onlookers that the patient is being arrested for an 
BOX 3 Common misconceptions in relation to care under Section 136

1 Regular use of custody suite as a place of safety is acceptable

2 Police should routinely transport the patient to a place of safety

3 The police should be expected to remain at the place of safety until assessment is complete

4 Community teams should staff the Section 136 suite

5 It is not important for the first doctor who does a Mental Health Act assessment to have Section 12 approval

6 There is no advantage in waiting for the approved mental health practitioner to begin the mental health assessment

offence, which is potentially embarrassing for the individual, especially if witnessed by friends or neighbours. A swift response from the ambulance service would resolve this issue and ambulance clinicians may contribute to the care by identifying medical issues requiring ongoing attention from an emergency department.

'The police should remain at the place of safety until the assessment is completed'

In some areas the police are expected to perform the role of mental health professionals by routinely supporting the care of the patient under Section 136 in a healthcare setting. Clearly they are not trained for this role and again it criminalises the process, as explained above. It should never be seen as the solution to shortages in mental health staff.

\section{'Community teams should staff the Section 136 suite'}

The crisis resolution/home-treatment team (CRHT) and other community staff may have neither the required competencies nor the ability to attend the suite at short notice. There are accounts of patients waiting in police vehicles for staff to attend the Section 136 suite. Community staff may find it more difficult to summon additional staff where the patient is disturbed and this increases the risk of undue reliance on police to provide support or the custody suite being used instead.

'It is not important for the first doctor who does a Mental Health Act assessment to have Section 12 approval'

Whereas it is not mandatory, the danger here is that a doctor without the required expertise may wrongly determine that the person does not require further assessment.
'There is no advantage in waiting for the approved mental health practitioner to begin the mental health assessment'

A patient who does not require admission may not agree to wait for the approved mental health practitioner and so receive less advice and support in relation to their social circumstances.

\section{Standards for the physical environment of the Section 136 suite}

The suite must be suitable for patients who may remain there for prolonged periods (occasionally more than 24 hours). It must support the assessment process and should enable a disturbed patient to be safely managed in line with NICE Clinical Guideline 25 (National Institute for Health and Clinical Excellence 2005) (Box 4). Thus, the facility should be locked, spacious and airy, with a place for the patient to lie down and with access to snacks, drinks and toilet facilities. For safety purposes, there should be good exits from the interview room, furniture that cannot be used to cause injury, an alarm system that will summon

\section{BOX 4 Requirements of a Section 136 suite}

\section{Interview room}

- Size sufficient for six people and physical intervention

- Two exits, opening outwards, and an observation window

- Washable furniture that cannot cause injury if thrown

- Panic alarm, ligature point check, possibly CCTV

- Easy for extra staff to attend in an emergency

- Access to resuscitation equipment

\section{Supporting facilities}

- Office for staff to meet and write notes

- Computer linked to healthcare system, phone and access to photocopier

- Couch for sleeping or resting and for medical examination; may be within the interview room

- Washing and toileting facilities

- Provision of beverages and light snacks

- Medication cupboard or easy access to medication

- Place for carers to wait

Location

- Unit should be accessible for disabled people and preferably on ground floor

- Quiet location as patient may want to rest

- Discreet access to avoid public areas to protect dignity

- Secure area so patient has space to wander and to speak with carers. 
extra staff (and such staff should be available), and access to resuscitation equipment and emergency medication.

\section{Information on current standards of care}

The lack of reliable data on the use of Section 136 is unsurprising given that the Section 136 pathway spans at least three provider organisations (police, healthcare provider and social services) and may include up to six professional groups in five provider organisations. Furthermore, it is the only civil detention under the Mental Health Act that has no statutory documentation. In London, UK, discrepancies of 30-50\% have been found in recording rates between health services and the police (Bather 2006). This may be one explanation for the lack of research in this area for the past 10 years.

\section{Monitoring of Section 136 standards of care}

Collection of routine data should first ensure that where care falls short of national guidance the identified problems are rapidly addressed. Second, it should support research into how the need for Section 136 can be reduced by, for example, changes to community care delivery. National benchmarking can facilitate service improvement so a minimum dataset would support both service development and research. The information required according to the national guidance is listed in Box 5.

In addition, a patient and carer survey should be carried out periodically to review the patient and carer experience of the care provided.

\section{Potential advantage of a standard monitoring form}

To assist in the collection of comparable data, a model form was included in CR149 (Royal College of Psychiatrists 2008) based on the form then in use by the Metropolitan Police. This was piloted and a simplified three-page version has recently been published in CR159 (Royal College of Psychiatrists 2011: Appendix 1). It is now in use in London, Nottinghamshire and Oxfordshire. In addition to the key information required for the Codes of Practice, it records data on the number of patients intoxicated, the need for restraint before admission, any criminal activity and provision of written and verbal information to the patient about Section 136. Recording times of all interventions allows variance from the care pathway to be reviewed. For example, delays in initiating the patient interview may be found to reflect staffing levels at certain times or the number of patients too intoxicated to be interviewed within 3 hours.
BOX 5 Requirements of routine monitoring

- How often Section 136 is used

- The characteristics of those detained, including age, gender and ethnicity

- The place of safety used. Where this is not the Section 136 suite, reasons should be given

- Any transfers between places of safety and reasons for them

- The means of conveyance and reasons given if not an ambulance

- Time for the approved mental health practitioner to commence the assessment

- Time for the first doctor to begin the assessment

- Whether the first doctor was Section 12 approved

- Time to complete the assessment

- Time for which police supported healthcare staff at place of safety

- Outcome of assessment (admission, formal or informal, discharge with or without community follow-up)

- Time in Section 136 suite (to determine delays in transfer or discharge)

- Serious untoward incidents

Members of the Royal College of Psychiatrists interested in using the revised Section 136 monitoring form are invited to contact me by post or email (addresses are given on the first page of this article).

\section{Key standards in relation to Section 136}

To highlight key factors in relation to care under Section 136, the group who developed the College guidance identified four key standards. These are:

- the custody suite should be used on an exceptional basis only;

- ambulance vehicles should be used wherever possible to convey to the place of safety;

- the doctor conducting the first medical assessment for the purposes of the Mental Health Act should be approved under Section 12 of the Act; and

- the approved mental health practitioner should commence the assessment within 3 hours unless there are valid reasons to delay the interview.

It is recommended that evidence should be gathered in relation to these standards for benchmarking.

\section{Local Section 136 policy implementation groups}

It is the responsibility of the commissioners to ensure that there is a multi-agency group to develop 
and implement a local policy and to monitor its effectiveness. This could be an additional task for an existing group, such as a police liaison group. It should include representation of all of the professionals involved in the Section 136 process, including user and carer representation.

In Nottinghamshire, for example, a commissioner chairs the group covering two Section 136 facilities, in Mansfield and Nottingham. The group meets bimonthly and reviews the data collated from the monitoring forms. This has ensured that the majority of assessments take place in the Section 136 suites and a gradual increase in the use of ambulance vehicles for conveyance. Individual problems are taken to the line managers on a case-by-case basis as they arise, but ways of addressing key themes, such as the impact of the increased use of Section 136 following the opening of the Section 136 suites, are discussed in the meeting and learning in relation to the legislation is shared. The monitoring group has also facilitated multidisciplinary training.

\section{References}

Bather P (2006) Review of Section 136 Mental Health Act. London Development Centre.

Department of Health (2008) Mental Health Act 1983: Code of Practice. TSO (The Stationery Office).

Home Office (2006) Police and Criminal Evidence Act 1984: Code of Practice C (Code of Practice for the Detention, Treatment and Questioning of Persons by Police Officers). TSO (The Stationery Office).

Docking M, Menin S (2007) Deaths During or Following Police Contact. Statistics for England and Wales 2006/2007. Independent Police Complaints Commission.

Mental Health Act Commission (2009) Coercion and Consent: Thirteenth Biennial Report 2007-2009. TSO (The Stationery Office)

National Institute for Health and Clinical Excellence (2005) Violence: The Short-Term Management of Disturbed/Violent Behaviour in In-Patient Psychiatric Settings and Emergency Departments (CG25). NICE.

Royal College of Psychiatrists (2008) Standards on the Use of Section 136 of the Mental Health Act 1983 (2007) (Version for England) (College Report CR149). Royal College of Psychiatrists (http://www.rcpsych.ac.uk/ publications/collegereports/cr/cr149.aspx).

Royal College of Psychiatrists (2011) Standards on the Use of Section 136 of the Mental Health Act 1983 (England and Wales) (College Report CR159). Royal College of Psychiatrists (http:// http://www.rcpsych.ac.uk/ publications/collegereports/cr/cr159.aspx).

Welsh Assembly Government (2008) Mental Health Act (1983): Code of Practice for Wales. Welsh Assembly Government.

\section{MCOs}

Select the single best option for each question stem

1 In transferring the patient under Section 136 to a place of safety:

a if a police vehicle is present, this should be used to remove the patient promptly from the public place

b the ambulance clinician can be responsible for conveying the patient to the place of safety

c the police should accompany the patient to the place of safety

$d$ the place of safety can be chosen by ambulance staff

e the nearest place of safety should always be used.
2 The following can be used as places of safety:

a a residential home

b an adolescent unit

c a day centre

$\mathrm{d}$ none of the above

e all the above.

3 If a patient is formally assessed by a doctor without Section 12 approval as no longer meeting criteria for detention:

a the patient still needs to wait to see a doctor with Section 12 approval or an approved mental health practitioner

b the police should provide transport from a custody suite

c they should be advised to wait to see an approved mental health practitioner

$d$ they will not need aftercare

e there is a duty to inform the carers of this decision.
4 The following are recommended for monitoring:

a time to call the doctor from commencement of Section 136

b whether patient was intoxicated

c conveyance home from place of safety

$\mathrm{d}$ the place of birth of the patient.

e all of the above.

5 The following is true:

a a medical ward is regarded as a 'public place' in relation to Section 136

b the power that enables the police to search the patient is in the Mental Health Act legislation

c a patient should not be interviewed if under the influence of alcohol

$d$ if a significant offence has occurred it is preferable to arrest the person

e the police must include the Section 136 details in a criminal record check. 